\title{
Shame, perceived knowledge and satisfaction associated with mental health as predictors of attitude patterns towards help-seeking
}

\author{
N. Rüsch ${ }^{1,2 *}$, M. Müller ${ }^{1}$, V. Ajdacic-Gross ${ }^{1}$, S. Rodgers ${ }^{1}$, P.W. Corrigan ${ }^{3}$ and W. Rössler ${ }^{1}$ \\ ${ }^{1}$ Department of Psychiatry, Psychotherapy and Psychosomatics, Psychiatric University Hospital Zürich, Switzerland \\ ${ }^{2}$ Department of Psychiatry II, University of Ulm, Germany \\ ${ }^{3}$ Illinois Institute of Technology, Chicago, USA
}

\begin{abstract}
Aims. To examine stigma- and knowledge-related barriers to help-seeking among members of the general population.
Methods. In a representative survey of young to middle-aged Swiss adults $(n=8875)$, shame about a potential own mental illness, perceived knowledge about and satisfaction with one's mental health, psychiatric symptoms and attitudes towards help-seeking were assessed.
\end{abstract}

Results. A latent profile analysis of all participants yielded two groups with different attitudes towards help-seeking. Relative to the majority, a one-in-four subgroup endorsed more negative attitudes towards seeking professional help, including psychiatric medication, and was characterized by more shame, less perceived knowledge, higher satisfaction with their mental health, younger age, male gender and lower education. Among participants with high symptom levels $(n=855)$, a third subgroup was reluctant to seek help in their private environment and characterized by high symptoms as well as low satisfaction with their mental health.

Conclusions. Shame as an emotional proxy of self-stigma as well as poor subjective mental health literacy may be independent barriers to help-seeking. Interventions to increase mental health service use could focus on both variables and on those individuals with more negative views about professional help, in the general public as well as among people with a current mental illness.

Received 15 February 2013; Revised 23 April 2013; Accepted 24 April 2013; First published online 18 July 2013

Key words: Attitudes to help-seeking, knowledge, satisfaction with mental health, shame.

\section{Introduction}

Most people with mental illness are not treated (Thornicroft, 2007). Even in developed countries roughly half of those with severe psychiatric disorders and about two-thirds with less severe disorders do not receive professional help (Wang et al. 2007; Thornicroft, 2012), a cause of personal suffering and socioeconomic costs (King et al. 2013). Potential sources of treatment or support include professional help, with general practitioners often acting as gate keepers to specialist services such as psychotherapy or psychiatric medication (Huxley, 1996), and informal help such as ministers from one's faith community or friends and family. Among members of the general public, friends and relatives as sources of help are often seen more

* Address for correspondence: Dr N. Rüsch, Section of Public Mental Health, Department of Psychiatry II, University of Ulm, Parkstrasse 11, 89073 Ulm, Germany.

(Email: nicolas.ruesch@uni-ulm.de) positively than mental health services (Jorm \& Wright, 2007). As a consequence, different studies have investigated attitudes to one particular treatment, e.g. psychiatric medication or general practitioners (Rüsch et al. 2009c, 2011), to professional help in general (Schomerus et al. 2012a) or to both professional and informal sources of help (Jorm \& Wright, 2007).

So far most research in this field has used a variablecentred approach, examining attitudes towards different kinds of help-seeking as single variables. However, both the general public and people with mental illness probably show substantial heterogeneity in the patterns or profiles of their attitudes. Findings based on a heterogeneous overall sample may be of little value to predict attitude patterns and behaviours in more homogeneous subgroups, limiting the utility of such variable-centred approaches. Therefore, personcentred analytic approaches have attracted increasing attention in recent years (von Eye \& Bergman, 2003), among them latent profile analysis. This method partitions a large sample into latent, or unobserved, 
categorical classes, determining homogeneous subgroups of respondents in the larger heterogeneous population. Findings from this approach can be applied to interventions: Specific homogeneous subgroups, such as persons with more negative attitudes towards seeking professional help, could be the focus of interventions that aim to increase service use (von Eye \& Bergman, 2003).

Three barriers to help-seeking have attracted increasing attention to explain low rates of service use: stigma of mental illness and shame as its emotional consequence; knowledge about mental health or mental health literacy; and satisfaction with one's mental health, a concept related to perceived need for treatment. Stigma and discrimination associated with mental illness are common (Angermeyer \& Dietrich, 2006; Rose et al. 2011; Schomerus et al. 2012b; Lasalvia et al. 2013) and can act as barriers to helpseeking and prevention in different ways (Corrigan \& Rüsch, 2002; Phelan et al. 2006; Schomerus \& Angermeyer, 2008; Clement et al. 2012; Lanfredi et al. 2013). People with mental illness may avoid helpseeking due to fear of being discriminated against by others (public stigma) or because they agree with negative stereotypes and turn them against themselves (self-stigma) (Vogel et al. 2006; Rüsch et al. 2009a; Evans-Lacko et al. 2012). Shame about one's mental illness is strongly related to self-stigma and can therefore be considered self-stigma's emotional side (Rüsch et al. 2006, 2007b). Shame and embarrassment were identified as barriers to help-seeking in a number of recent studies (Edlund et al. 2002; Barney et al. 2006; Jorm et al. 2007a, b; Jagdeo et al. 2009; Schomerus et al. 2009).

A second barrier is poor mental health literacy or the lack of knowledge about mental illnesses, including their recognition, prevention and available treatments (Jorm, 2012). Jorm et al. (2000) have found accumulating evidence for the link between better mental health literacy and more positive attitudes to seeking professional help and service use. So far, mental health literacy has been measured as objective knowledge of mental health-related facts. It is unclear whether perceived knowledge about mental health, or subjective mental health literacy, plays a similar role for help-seeking.

Third, in order to seek help, people with mental illness need to be dissatisfied with their mental health and to perceive need for help. Research has shown that two thirds of people with mental disorders do not feel they need help (Codony et al. 2009). A recent pilot study found that the negative effect of stigmatizing attitudes on help-seeking was partly mediated by not appraising their present difficulties as mental health problems (Schomerus et al. 2012a). Last, psychiatric symptoms often lower the satisfaction with one's mental health and increase perceived need for help, but are also associated with shame (Rüsch et al. 2007a). Measuring psychiatric symptoms allows us to examine predictors of attitudes towards help-seeking in two equally important groups: the general public v. those respondents with high levels of psychiatric symptoms.

Given these findings, this study had three aims: (i) to identify subgroups of participants with homogeneous profiles of attitudes towards seeking help from different sources, ranging from professional mental health services to help from family and friends; (ii) to examine how these different subgroups are characterized by the shame associated with mental illness, perceived knowledge about and satisfaction with one's mental health; (iii) to assess the direct and indirect effects of psychiatric symptoms on help-seeking attitudes. We studied these three issues both in a large general population sample and in a subgroup with high symptom levels, controlling our analyses for age, gender and education level.

\section{Methods \\ Participants}

The data were collected in the epidemiological project of the Zürich Program for the Sustainable Development of Mental Health Services (www.zinep.ch). In a representative epidemiological survey of young to middle-aged adult Swiss citizens in the canton of Zürich, Switzerland, with a total population of about 1.4 million, $N=8875$ individuals $(50.1 \%$ male) were interviewed by a social research company using computer assisted telephone interviews. All municipalities within the canton of Zürich were contacted and within each a specific number of addresses was randomly selected. The current study was designed as a crosssectional survey, different from the longitudinal Zürich Study which started in 1978 and included a representative sample of subjects who were then 19 (males) or 20 (females) years old, respectively, following them up for over thirty years in altogether seven assessments (Angst et al. 1984, 2009). The current study recruited a cross-sectional sample comparable in age and gender to the Zürich Study, limited to its first six assessments (Ajdacic-Gross et al., submitted). Therefore six female $(n=846,22$ years; $n=669,24$ years; $n=672,29$ years; $n=819,31$ years; $n=639,36$ years; $n=782,42$ years) and six male $(n=966$, 21 years; $n=720,23$ years; $n=677,28$ years; $n=619$, 30 years; $n=742,35$ years; $n=724,41$ years) subsamples of corresponding age groups were included. The study was approved by the ethics committee of the canton of Zürich. 


\section{Measures}

Attitudes towards help seeking

Respondents were asked whether they thought the following seven types of help seeking could be recommended for someone in psychological distress, from 0 (not at all) to 4 (very much): go to general practitioner; go to psychiatrist/psychologist; take psychiatric medication; go to minister/priest; talk to partner and family; talk to friends and acquaintances; wait and do nothing. Finally, respondents were asked whether they themselves would use mental health services in case they felt down or low about a longer period $(1=$ probably not, $2=$ undecided, $3=$ probably yes).

\section{Predictor variables}

Shame about a potential mental illness was examined in response to the question 'Would you feel ashamed if you had a mental illness?', from 1 (not at all) to 5 (very much). Participants rated their perceived knowledge about mental health answering the question 'What do you think, how good is your knowledge about mental health and stress?', with 1 (rather bad), 2 (average) or 3 (rather good). Satisfaction with one's mental health was assessed by the response to the question 'How satisfied are you specifically with your mental health?', from 1 (not satisfied at all) to 5 (very satisfied). The level of psychiatric symptoms in the past week was assessed by the 27-item version of the Symptom Check List (SCL-27; Hardt, 2008), yielding a mean score between 0 and 4 . Analyses were controlled for age, gender and education as potential confounder variables. Education was assessed ranging from the minimum number of 8 years in school (lowest) to a completed university degree (highest), yielding an eight-level ordinal variable.

\section{Statistical analyses}

All analyses were done separately for the entire group of participants $(n=8875)$ and for those with high symptom levels $(n=855)$, defined following the SCL-90-R Manual and its 'caseness' definition (Derogatis, 1977) as in the previous research (Müller et al. 2010). Thus participants with SCL-27 mean scores above the 90th percentile (among all 8875 participants) were considered high scorers. Analyses were conducted using MPlus statistical modelling software, version 6.0 (Muthén \& Muthén, 2011).

Proportions are provided for categorical variables or means and standard deviations for continuous variables, respectively. Associations between predictor variables were assessed by bivariate correlations (Table 1). The main analysis was conducted in two steps. The first step was intended to detect patterns of attitudes to help-seeking using the eight attitude items described above. We used Latent Profile Analysis (LPA; McLachlan \& Peel, 2000) to identify distinct patterns of attitudes towards help-seeking. LPA identifies homogeneous groups of individuals based on similarities of response patterns and has been described as person-centred counterpart to factor analysis which, unlike LPA, aims to find similar sets of variables (Muthén \& Muthén, 2002).

Table 1. Descriptive statistics and bivariate correlations for the entire sample ( $n=8875)$; in parentheses for participants with high levels of psychiatric symptoms $(n=855)$

\begin{tabular}{|c|c|c|c|c|c|c|c|}
\hline & & $\begin{array}{c}\text { Gender }(\text { male }=1, \\
\text { female }=2)\end{array}$ & Age & Education & $\begin{array}{l}\text { Psychiatric } \\
\text { symptoms }\end{array}$ & Shame & $\begin{array}{l}\text { Perceived } \\
\text { knowledge }\end{array}$ \\
\hline Gender & 50.1 & - & & & & & \\
\hline$\%$ male & (39.3) & & & & & & \\
\hline Age & $29.9 \pm 7.0 ; 21-42$ & $0.10^{* * *}$ & - & & & & \\
\hline $\mathrm{M} \pm$ s.D.; range & $(29.5 \pm 6.9 ; 21-42)$ & $(-0.02)$ & & & & & \\
\hline Education level & 19.0 & 0.01 & $0.37^{* * *}$ & - & & & \\
\hline$\%$ highest degree & $(12.5)$ & $(0.01)$ & $\left(0.33^{* * *}\right)$ & & & & \\
\hline Psychiatric symptoms & $0.5 \pm 0.4 ; 0-3.2$ & $0.11^{* * *}$ & $-0.07^{* * *}$ & $-0.09^{* * *}$ & - & & \\
\hline $\mathrm{M} \pm$ S.D.; range & $(1.5 \pm 0.4 ; 1.1-3.2)$ & $\left(0.09^{* *}\right)$ & $(0.02)$ & $(-0.04)$ & & & \\
\hline Shame & $2.1 \pm 1.0 ; 1-5$ & $-0.06^{* * *}$ & $-0.07^{* * *}$ & $0.07^{* * *}$ & $0.14^{* * *}$ & - & \\
\hline $\mathrm{M} \pm$ s.D.; range & $(2.3 \pm 1.2 ; 1-5)$ & $(-0.04)$ & $(-0.06)$ & $(0.04)$ & $(0.03)$ & & \\
\hline Perceived knowledge & $2.3 \pm 0.7 ; 1-3$ & $0.20^{* * *}$ & $0.15^{* * *}$ & $0.13^{* * *}$ & $0.06^{* * *}$ & $-0.14^{* * *}$ & - \\
\hline $\mathrm{M} \pm$ s.D.; range & $(2.4 \pm 0.7 ; 1-3)$ & $\left(0.07^{*}\right)$ & $\left(0.14^{* * *}\right)$ & $\left(0.12^{* * *}\right)$ & $(0.06)$ & $\left(-0.14^{* * *}\right)$ & \\
\hline Satisfaction & $4.2 \pm 0.9 ; 1-5$ & $-0.07^{* * *}$ & -0.01 & $0.08^{* * *}$ & $-0.54^{* * *}$ & 0.01 & $-0.08^{* * *}$ \\
\hline $\mathrm{M} \pm$ S.D.; range & $(3.1 \pm 1.0 ; 1-5)$ & $(-0.04)$ & $\left(-0.11^{* * *}\right)$ & $(0.02)$ & $\left(-0.36^{* * *}\right)$ & $(0.02)$ & $\left(-0.14^{* * *}\right)$ \\
\hline
\end{tabular}

${ }^{* * *} p<0.001,{ }^{* *} p<0.01,{ }^{*} p<0.05$. 
LPA is ideally suited to explore possible subpopulations within a population-based sample because it simultaneously evaluates all items submitted to the analysis and yields fit statistics to test and compare multiple class solutions. Accordingly, starting with a single (total sample) class solution, we tested solutions with increasing numbers of classes and model fit statistics indicated the best fitting solution. For that purpose we evaluated the relative fit of different models by the Lo-Mendell-Rubin adjusted likelihood ratio test (LMR-A; Lo et al. 2001), the Bayesian information criterion (BIC) and the sample-size-adjusted BIC (BIC-A), and the Aikaike information criterion (AIC; McLachlan \& Peel, 2000). Significant LMR-A values suggest that a model is preferable over another model with the next lower number of classes. A non-significant LMR-A value indicates that the solution includes too many classes (Nylund et al. 2007). For the sake of parsimony, solutions with one or several classes including less than $5 \%$ of all participants were rejected.

Following the latent profile analysis, we used class membership as categorical dependent variable in a multinomial logistic regression model. Since the class solutions were estimated based on responses to items that assessed attitudes to help-seeking, class membership indicates patterns or profiles of such attitudes. In all regressions, we determined predictors of membership in one class relative to the group with most participants as the majority reference class. We examined two groups of predictors: first, the level of psychiatric symptoms, controlling for sociodemographic variables as potential confounders (gender, age, education); second, shame, perceived knowledge and satisfaction associated with mental health. For the latter three predictors, we examined their direct effects as well as their role as mediators between sociodemographic variables/symptoms and class membership (Fig. 1). To estimate mediation, two models were calculated: first the unmediated direct effects of all seven variables on class membership; second, the indirect effects of symptoms or sociodemographic variables on group membership - mediated by shame, perceived knowledge and satisfaction - were added. Indirect effects are the products of two parameter estimates: (i) from the distal predictor (symptoms) or sociodemographic variable to the mediating variable (e.g., shame) and (ii) from the mediating variable to group membership. Probabilities of both direct and indirect effects are provided by odds ratios (OR) with $95 \%$ confidence intervals $(95 \% \mathrm{CI})$, an indirect effect being significant if the $95 \%$ CI did not include 1.0 (Tables 3 and 4).

\section{Results}

\section{Associations between predictor and sociodemographic variables}

Summarizing findings with correlation coefficients greater than 0.10 (Table 1), in the entire sample higher

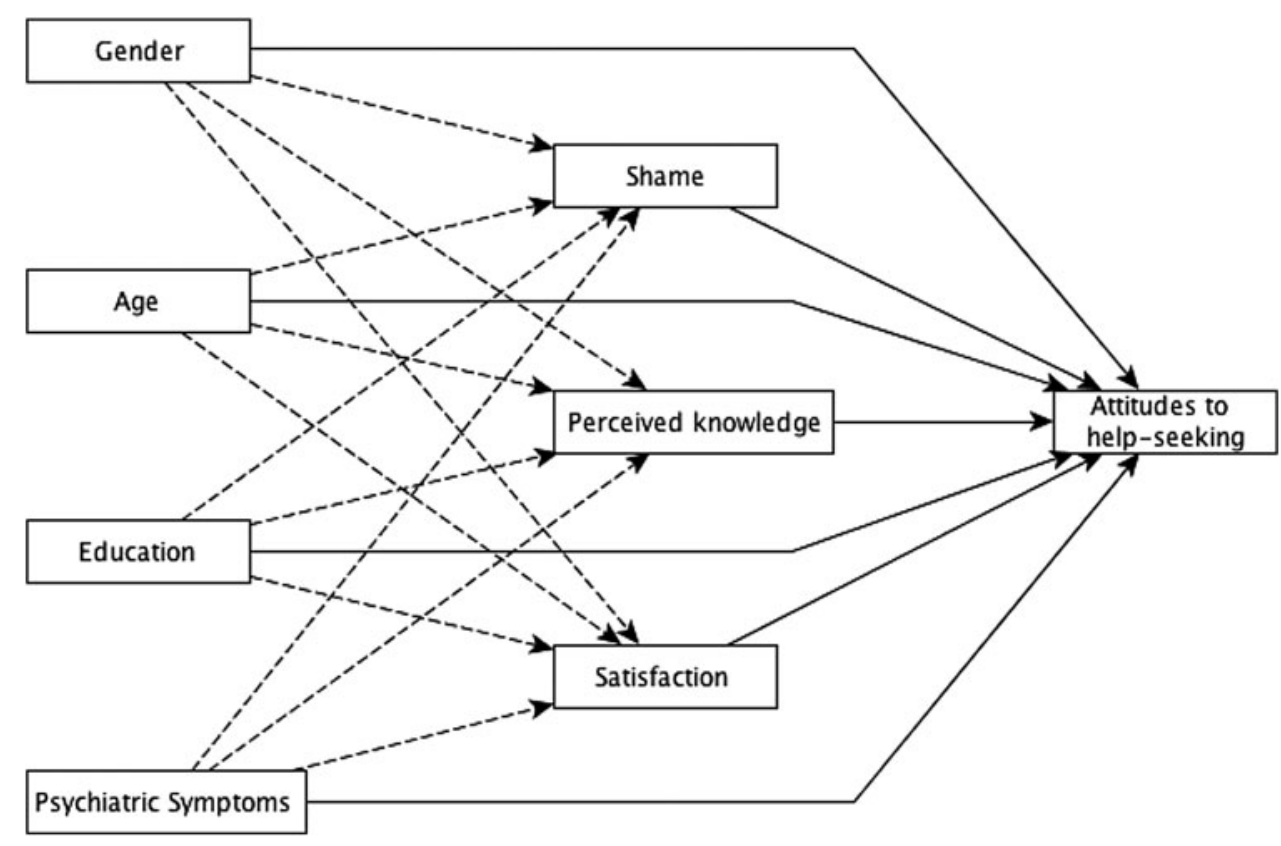

Fig. 1. Model of sociodemographics and psychiatric symptoms (left column) as well as shame, perceived knowledge and satisfaction as predictors of attitudes to help-seeking. Dashed arrows indicate the first part of an indirect pathway from sociodemographic variables or symptoms (left) to help-seeking attitudes (right), mediated by shame, knowledge or satisfaction. 
Table 2. Latent Profile Analysis, goodness of fit statistics for the entire sample $(n=8875)$ in the top half of this table; and for participants with high levels of psychiatric symptoms $(n=855)$ in its lower half. From left to right, multiple solutions are presented with increasing numbers of classes. Bold print indicates the best fitting solutions, the basis of further analyses (Tables 3 and 4)

\begin{tabular}{|c|c|c|c|c|c|}
\hline$[n=8875]$ & 1 class & 2 classes & 3 classes & 4 classes & 5 classes \\
\hline AIC & 191421.05 & 181745.81 & 175421.68 & 158198.93 & 154358.77 \\
\hline $\mathrm{BIC}$ & 191534.50 & 181923.09 & 175662.77 & 158503.85 & 154727.50 \\
\hline BIC-A & 191483.66 & 181843.64 & 175554.73 & 158367.20 & 154562.25 \\
\hline LMR & na & $\begin{array}{c}2 v .1: 9576.20 \\
p<0.0001\end{array}$ & $\begin{array}{c}3 v .2: 6265.55 \\
p=0.10\end{array}$ & $\begin{array}{c}4 v \cdot 3: 17070.05 \\
p=0.16\end{array}$ & $\begin{array}{c}5 \text { v. } 4: 3823.12 \\
p<0.0001\end{array}$ \\
\hline$N$ for each class $(\mathrm{C})$ & $C=8875$ & $\begin{array}{l}C 1=6651 \\
C 2=2224\end{array}$ & $\begin{array}{r}C 1=732 \\
C 2=6616 \\
C 3=1527\end{array}$ & $\begin{array}{r}C 1=591 \\
C 2=6616 \\
C 3=1527 \\
C 4=141\end{array}$ & $\begin{array}{r}C 1=141 \\
C 2=961 \\
C 3=1529 \\
C 4=5653 \\
C 5=591\end{array}$ \\
\hline$[n=855]$ & 1 class & 2 classes & 3 classes & 4 classes & 5 classes \\
\hline AIC & 19661.60 & 19103.16 & 18460.00 & 18085.56 & 16892.37 \\
\hline BIC & 19737.62 & 19221.94 & 18621.54 & 18289.86 & 17139.43 \\
\hline BIC-A & 19686.81 & 19142.55 & 18513.57 & 18153.30 & 16974.29 \\
\hline LMR & na & $\begin{array}{c}2 v .1: 567.11 \\
p<0.0001\end{array}$ & $\begin{array}{c}3 \text { v. 2: } 271.46 \\
p=0.01\end{array}$ & $\begin{array}{c}4 v .3: 386.09 \\
p=0.001\end{array}$ & $\begin{array}{c}5 \text { v. } 4: 230.92 \\
p=0.18\end{array}$ \\
\hline$N$ for each class $(\mathrm{C})$ & $C=855$ & $\begin{array}{l}C 1=715 \\
C 2=140\end{array}$ & $\begin{array}{l}C 1=541 \\
C 2=211 \\
C 3=103\end{array}$ & $\begin{array}{r}\mathrm{C} 1=22 \\
\mathrm{C} 2=587 \\
\mathrm{C} 3=174 \\
\mathrm{C} 4=72\end{array}$ & $\begin{array}{r}C 1=28 \\
C 2=553 \\
C 3=115 \\
C 4=66 \\
C 5=93\end{array}$ \\
\hline
\end{tabular}

AIC: Aikaike Information Criterion; BIC: Bayesian Information Criterion; BIC-A: sample-adjusted BIC; LMR: Lo-Mendell-Rubin adjusted likelihood ratio test.

symptoms were associated with female gender, more shame and less satisfaction about one's mental health. Better perceived knowledge was related to female gender, older age, better education and less shame.
Among participants with high symptom levels, correlation patterns were similar (Table 1 , numbers in parentheses) except for weaker associations of symptoms with shame and satisfaction.

Table 3. Predictors of membership in the subgroup with more negative attitudes towards help-seeking from professionals (class 2; relative to class 1, see Fig. 2A), assessed by path modelling and multi-nomial logistic regression among all participants $(n=8875)$

Predictors of class 2 membership (persons with negative attitudes towards help-seeking from professionals)

\begin{tabular}{|c|c|c|c|c|c|}
\hline \multirow[b]{2}{*}{ Predictor variables } & \multirow{2}{*}{$\begin{array}{l}\text { Model with direct } \\
\text { effects only }\end{array}$} & \multicolumn{4}{|c|}{ Mediation Model (direct and indirect effects) } \\
\hline & & $\begin{array}{l}\text { Direct effect } \\
\text { OR }(95 \% \text { CI) }\end{array}$ & $\begin{array}{l}\text { Indirect effect } \\
\text { (via shame) } \\
\text { OR }(95 \% \text { CI) }\end{array}$ & $\begin{array}{c}\text { Indirect effect } \\
\text { (via perceived } \\
\text { knowledge) } \\
\text { OR }(95 \% \mathrm{CI})\end{array}$ & $\begin{array}{l}\text { Indirect effect } \\
\text { (via satisfaction) } \\
\text { OR }(95 \% \mathrm{CI})\end{array}$ \\
\hline $\begin{array}{l}\text { Gender }(\text { male }=1 ; \\
\text { female }=2)\end{array}$ & $0.47(0.42-0.52)^{* * *}$ & $0.46(0.41-0.51)^{* * *}$ & $0.96(0.94-0.97) * * *$ & $0.88(0.86-0.90) * * *$ & $1.00(1.00-1.00)$ \\
\hline Age & $0.97(0.96-0.97)^{* * *}$ & $0.97(0.96-0.97)^{* * *}$ & $1.00(1.00-1.00)$ & $0.99(0.99-1.00)$ & $1.00(1.00-1.00)$ \\
\hline Education & $0.83(0.78-0.88)^{* * *}$ & $0.83(0.79-0.89)^{* * *}$ & $1.03(1.02-1.04) * * *$ & $0.97(0.96-0.98) * * *$ & $1.01(1.00-1.01)$ \\
\hline Psychiatric symptoms & $1.14(0.98-1.32)$ & $1.13(.97-1.30)$ & $1.11(1.08-1.13) * * *$ & $0.96(0.94-0.97) * * *$ & $0.89(0.82-0.96) * * *$ \\
\hline Shame & $1.33(1.27-1.40)^{* * *}$ & $1.34(1.27-1.41)^{* * *}$ & - & - & - \\
\hline Perceived knowledge & $0.57(0.53-0.61)^{* * *}$ & $0.58(0.54-0.63)^{* * *}$ & - & - & - \\
\hline Satisfaction & $1.11(1.03-1.20)^{* *}$ & $1.12(1.04-1.20)^{* *}$ & - & - & - \\
\hline
\end{tabular}

${ }^{* * *} p<0.001,{ }^{* *} p<0.01$, significant OR in bold print. 
Table 4. Predictors of membership in subgroups with negative attitudes towards help-seeking from professionals (class 2) or in one's private environment (class 3; relative to class 1, respectively, see Fig. 2B) among participants with high levels of psychiatric symptoms $(n=855)$

Predictors of class 2 membership (persons with negative attitudes towards help-seeking from professionals)

\begin{tabular}{|c|c|c|c|c|c|}
\hline \multirow[b]{2}{*}{ Predictor variables } & \multirow{2}{*}{$\begin{array}{l}\text { Model with direct } \\
\text { effects only } \\
\text { No mediator } \\
\text { OR }(95 \% \mathrm{CI})\end{array}$} & \multicolumn{4}{|c|}{ Mediation model (direct and indirect effects) } \\
\hline & & $\begin{array}{l}\text { Direct effect } \\
\text { OR }(95 \% \text { CI) }\end{array}$ & $\begin{array}{l}\text { Indirect effect } \\
\text { (via shame) } \\
\text { OR }(95 \% \mathrm{CI})\end{array}$ & $\begin{array}{l}\text { Indirect effect (via } \\
\text { knowledge) } \\
\text { OR }(95 \% \mathrm{CI})\end{array}$ & $\begin{array}{c}\text { Indirect effect (via } \\
\text { satisfaction) } \\
\text { OR }(95 \% \mathrm{CI})\end{array}$ \\
\hline $\begin{array}{l}\text { Gender }(\text { male }=1 ; \\
\quad \text { female }=2)\end{array}$ & $0.54(0.38-0.76)^{* * *}$ & $0.50(0.36-0.71)^{* * *}$ & $0.98(0.95-1.01)$ & $0.93(0.87-1.00)$ & $1.00(1.00-1.00)$ \\
\hline Age & $0.98(0.96-1.01)$ & $0.98(0.95-1.01)$ & $1.00(1.00-1.00)$ & $0.99(0.99-1.00)$ & $1.00(1.00-1.00)$ \\
\hline Education & $0.85(0.70-1.03)$ & $0.87(0.72-1.05)$ & $1.01(0.99-1.03)$ & $0.96(0.92-0.99)^{* * *}$ & $1.00(0.99-1.01)$ \\
\hline Symptoms & $0.78(0.47-1.28)$ & $0.81(0.50-1.32)$ & $1.02(0.98-1.06)$ & $0.92(0.84-1.00)$ & $0.94(0.78-1.09)$ \\
\hline Shame & $1.17(1.01-1.35)^{*}$ & $1.18(1.02-1.36)^{*}$ & - & - & - \\
\hline Perceived knowledge & $0.45(0.35-0.58)^{* * *}$ & $0.47(0.36-0.60)^{* * *}$ & - & - & - \\
\hline Satisfaction & $1.05(.87-1.26)$ & $1.07(0.90-1.29)$ & - & - & - \\
\hline \multicolumn{6}{|c|}{ Predictors of class 3 membership (persons with negative attitudes towards help-seeking in private environment) } \\
\hline \multirow{3}{*}{ Predictor variables } & Model with direct & \multicolumn{4}{|c|}{ Mediation Model (direct and indirect effects) } \\
\hline & No mediator & Direct effect & $\begin{array}{l}\text { Indirect effect } \\
\text { (via shame) }\end{array}$ & $\begin{array}{l}\text { Indirect effect (via } \\
\text { knowledge) }\end{array}$ & $\begin{array}{c}\text { Indirect effect (via } \\
\text { satisfaction) }\end{array}$ \\
\hline & OR $(95 \% \mathrm{CI})$ & OR $(95 \% \mathrm{CI})$ & OR $(95 \% \mathrm{CI})$ & OR $(95 \% \mathrm{CI})$ & OR $(95 \% \mathrm{CI})$ \\
\hline $\begin{array}{l}\text { Gender }(\text { male }=1 ; \\
\quad \text { female }=2)\end{array}$ & $0.71(0.45-1.12)$ & $0.66(0.42-1.03)$ & $1.02(0.98-1.05)$ & $1.00(0.97-1.04)$ & $1.01(0.97-1.04)$ \\
\hline Age & $1.01(0.98-1.04)$ & $1.01(0.98-1.04)$ & $1.00(1.00-1.01)$ & $1.00(1.00-1.00)$ & $1.01(1.00-1.01)$ \\
\hline Education & $0.85(0.67-1.07)$ & $0.84(0.67-1.06)$ & $0.99(0.97-1.01)$ & $1.00(0.98-1.02)$ & $0.99(0.97-1.01)$ \\
\hline Symptoms & $2.06(1.23-3.44)^{* *}$ & $1.97(1.19-3.28)^{* *}$ & $0.98(0.94-1.02)$ & $1.00(0.96-1.04)$ & $1.28(1.01-1.56) * * *$ \\
\hline Shame & $0.85(0.70-1.03)$ & $0.86(0.71-1.03)$ & - & - & - \\
\hline Perceived knowledge & $1.00(0.69-1.44)$ & $1.01(0.71-1.46)$ & - & - & - \\
\hline Satisfaction & $0.78(0.62-0.98)^{*}$ & $0.76(0.61-0.96)^{*}$ & - & - & - \\
\hline
\end{tabular}

${ }^{* * *} p<0.001,{ }^{* *} p<0.01,{ }^{*} p<0.05$, significant OR in bold print.

\section{LPA of attitudes towards help-seeking in the entire sample}

The LPA of all participants $(n=8875)$ yielded a twoclass solution with a significantly better fit than the single-class solution, while the three-class solution was not superior to the two-class solution (upper half of Table 2). Solutions with four or five classes included at least one class with a very small number of participants $(n<150 ;<2 \%)$. Therefore the two-class solution was the best fit with an approximate $75-$ $25 \%$ split (Fig. 2A).

Class 1 represents the majority of participants with on average positive views (above the scale midpoint of 2, Fig. $2 A$ ) about seeking help from a general practitioner, psychiatrist/psychologist, friends, family or about own mental health service use. On the other hand, majority attitudes on average were negative (well below the scale midpoint of 2) towards psychiatric medication, a minister/priest or doing nothing. Relative to class 1 , class 2 as an approximate $25 \%$-minority exhibited more negative attitudes towards professional help, including medication and towards own mental health service use.

\section{Predictors of attitudes to help-seeking in the entire sample}

To estimate the effects of predictor variables on membership in the class with more negative attitudes towards seeking professional help (class 2 in Fig. 2A) as compared to the majority (class 1 ), we ran two regressions (Table 3). In a first model, we only assessed direct effects and found that persons in the subgroup with more negative attitudes towards seeking professional help were characterized by higher levels of shame, less perceived knowledge and higher 
(a)

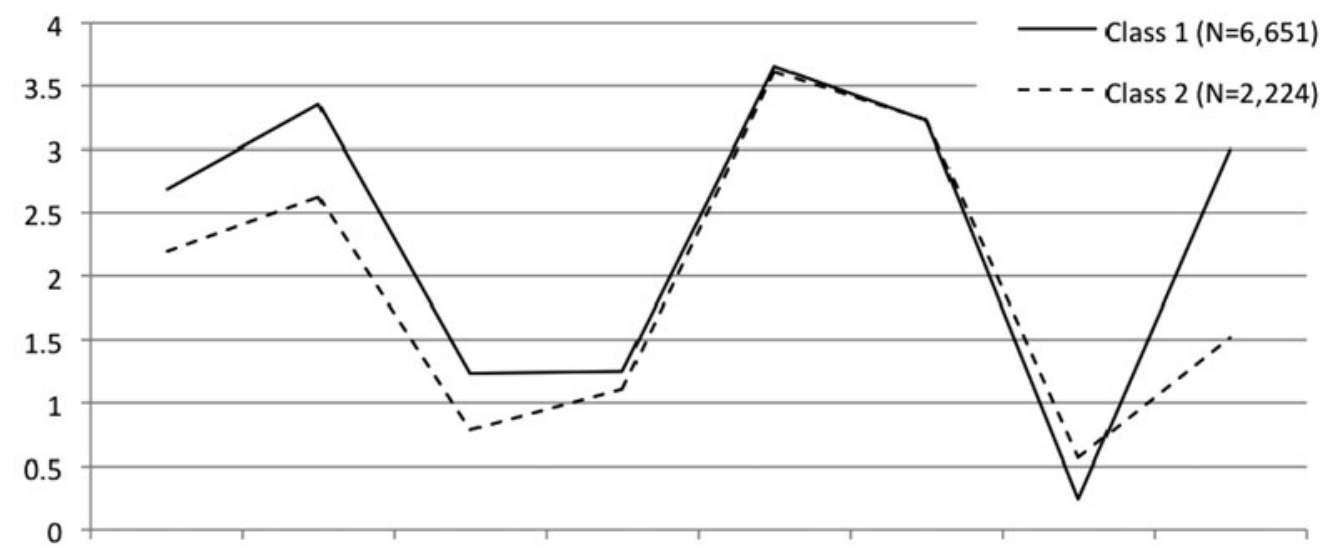

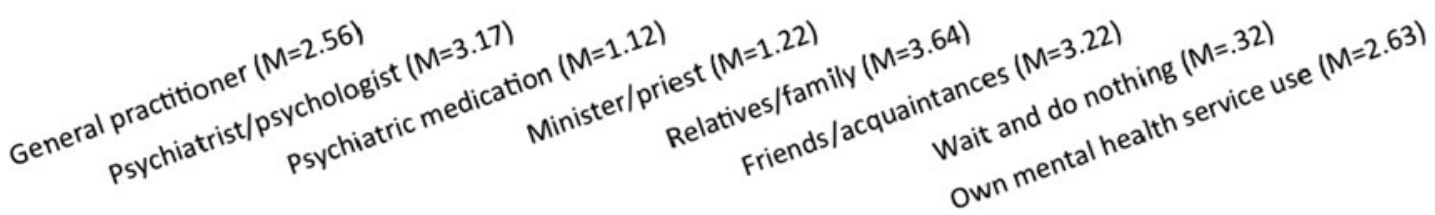

(b)

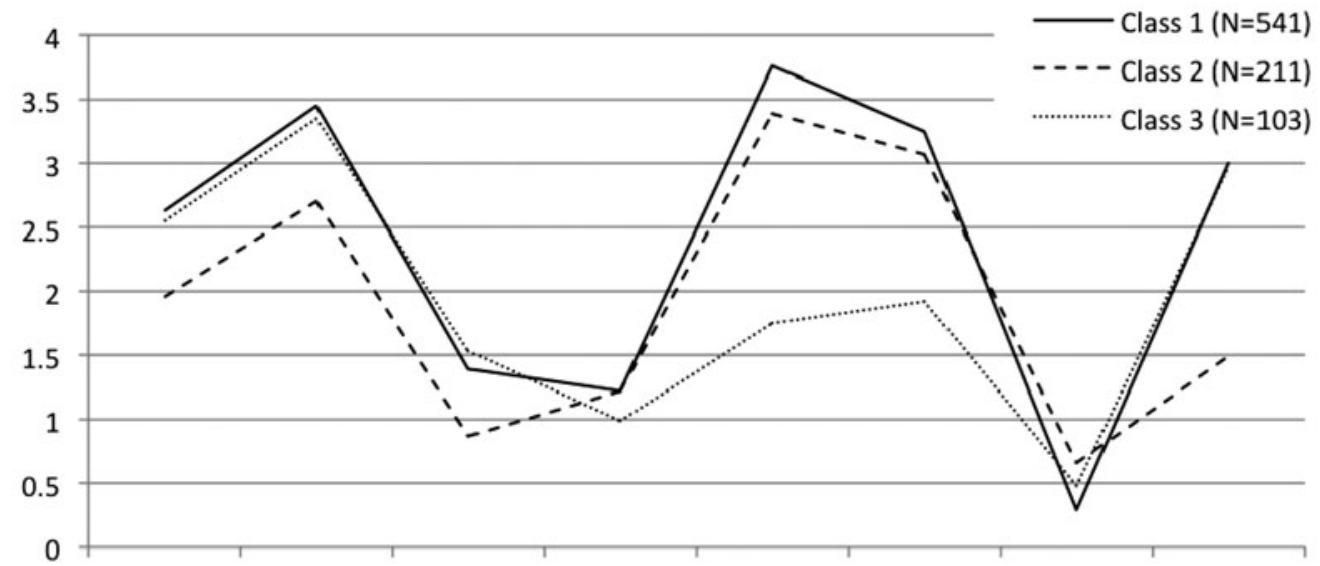

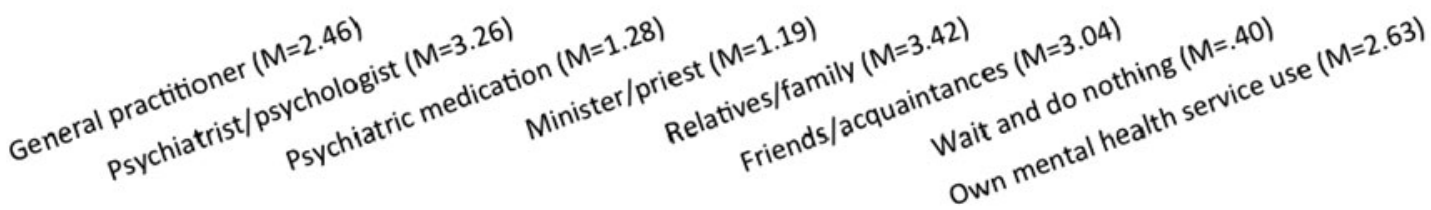

Fig. 2. Subgroups/classes of participants with different patterns of attitudes towards help-seeking, determined by Latent Profile Analysis: Part A with a two-class solution in the entire sample $(n=8875)$; part B with a three-class solution among participants with high levels of psychiatric symptoms $(n=855)$. Higher scores (vertical axis) indicate stronger agreement that this source of help should be sought (help-seeking recommendations scored 0 to 4 ; personal help-seeking intentions from 1 to 3 ).

satisfaction with their mental health as well as by being male, younger and less educated (Pseudo $R$-square $=0.10)$. In a mediation model assessing both direct and indirect effects (Table 3), all the direct effects remained significant.

The indirect effects of symptoms on attitudes to help-seeking had different directions, suggesting inconsistent mediation (MacKinnon et al. 2007) and explaining the lack of an overall correlation between symptoms and attitudes: more symptoms, mediated by increased shame, predicted more negative views on professional help-seeking; but more psychiatric symptoms were also associated with more positive views, mediated by decreased satisfaction and better perceived knowledge. Again showing inconsistent mediation, better education had different indirect effects on attitudes to professional help: via increased shame it was associated with more negative, but via better perceived knowledge with more positive attitudes. Finally, male gender was related to more negative attitudes, mediated by increased levels of shame and poorer perceived knowledge. 


\section{LPA among participants with high symptom levels}

The three-class solution (Fig. 2B) with an approximate $60-25-15 \%$ split of the high symptom group offered the best fit, significantly better than the two-class solution, which in turn was superior to the one-class solution (lower half of Table 2). The four- and five-class solutions were rejected due to classes with very few participants $(n<30 ;<4 \%)$. Classes 1 and 2 resembled the corresponding classes in the entire sample. Relative to class 1 as the majority, class 2 endorsed more negative attitudes towards professional help (Fig. 2B). Class 3 represented a smaller group of participants with much less positive views specifically about help-seeking in one's private environment.

\section{Predictors of attitudes to help-seeking among participants with high symptom levels}

Because the profile analysis (Fig. 2B) had yielded three classes, we ran two sets of regressions (see Table 4, upper and lower parts): to predict membership (i) in the subgroup with more negative attitudes towards help-seeking from professionals (class 2) and (ii) in the subgroup reluctant to seek help from one's private environment (class 3), both relative to the majority (class 1). Respondents with more negative attitudes towards professional help-seeking were independently characterized by more shame, less perceived knowledge and male gender (Table 4). Better education was indirectly associated with less negative attitudes, mediated by better perceived knowledge. Participants with greater scepticism to seek help among friends and family (class 3) were characterized by higher symptoms and less satisfaction with their mental health, with symptoms both having a direct and an indirect effect, the latter being mediated by lower satisfaction (Table 4).

\section{Discussion}

Using latent profile analysis, we found two groups with homogeneous attitude patterns towards helpseeking. Compared to the majority, approximately one-in-four endorsed more negative views towards professional mental health services including psychiatric medication, both in terms of recommendations to others and of using mental health services themselves. It should be noted that help-seeking recommendations for others were closely related to personal help-seeking intentions. Overall, respondents expressed more negative attitudes towards psychiatric medication relative to other sources of help which is consistent with previous surveys (Lauber et al. 2001; Riedel-Heller et al. 2005; Schomerus et al. 2012b).
With respect to our second aim to examine shame, perceived knowledge and satisfaction with one's mental health as predictors of attitudes, we found more shame, less perceived knowledge and higher satisfaction with one's mental health to be independent predictors of more negative views about professional sources of help. Therefore (anticipated) shame as a proxy of self-stigma as well as perceived poor knowledge would be useful targets for initiatives to improve attitudes towards professional sources of help.

In terms of knowledge as a concept, there are detailed measures of mental health literacy and its specific aspects, for example the Depression Literacy Scale to assess knowledge about depression including its symptoms and available treatments (Griffiths et al. 2004) or measures of more general knowledge about mental illness (Evans-Lacko et al. 2010). In our brief survey, it was not feasible to assess 'objective' mental health literacy which is a limitation of our study. Our measure could be considered an index of perceived knowledge or subjective mental health literacy. It does not indicate how much persons know, but whether they feel they know enough. The fact that perceived knowledge was associated with higher age, better education, more symptoms (increasing the likelihood of previous experience with mental illness) and with less shame would be consistent with this interpretation. However, our findings are preliminary and more research on subjective mental health literacy is needed.

As a third aim we examined the impact of symptoms on patterns of help-seeking attitudes. As summarized above, we found evidence for inconsistent mediation with different indirect effects. The pathway leading from more symptoms via increased shame to more negative attitudes is noteworthy. Anticipated shame about a potential own mental illness may become a less abstract emotional experience for respondents with high symptom levels. This process is analogous to self-stigma as a process that requires self-labelling as a person with mental illness so that stereotypes become relevant to oneself (Link, 1987; Corrigan \& Watson, 2002; Rüsch et al. 2009b, 2010). Symptoms and their recognition as signs of a mental illness might thus be a two-edged sword: They can facilitate help-seeking, but also induce fear of stigma and self-stigma (Jorm, 2012).

Comparing our findings between the entire sample and participants with high symptom levels, we found two remarkably similar subgroups, with respect both to their attitudes towards help-seeking and to the one-in-four size of those with more negative views about professional help. Persons with very high symptoms were more likely to belong to a third subgroup more hesitant to seek help in their private 
environment. This is consistent with findings that many people, with good reasons, tend to seek help from friends and family during low rather than during high levels of distress (Jorm et al. 2004).

Limitations of our study need to be considered. Our sample is representative of young and middle-aged adults in the Swiss region of Zürich and findings might differ among adolescents or the elderly or in other geographic regions. Data on perceived public and self-stigma (other than shame as its emotional proxy) as well as on previous social contact with persons with mental illness were not available. Since the label use affects help-seeking (Yap et al. 2013), selflabelling should be assessed in future studies. It is unclear how closely recommendations and intentions to seek help are related to actual behaviour. We did not distinguish between attitudes to help-seeking for different disorders. Different items in the survey referred to 'mental illness', 'psychological distress' or 'mental health'. Some variables were single items, precluding reliability tests. Our data were cross-sectional and do not allow conclusions on causality. Finally, the variance explained by our regression models was small. Other predictors were not accounted for and therefore future studies should include previous experiences with help-seeking as well as perceived quality and accessibility of services.

In conclusion, we found evidence for a sizeable subgroup of about one in four with distinctly more negative attitudes towards seeking help from professionals, both in the general population and among people with high symptom levels. This group was characterized by increased shame as a proxy of self-stigma and by poor subjective mental health literacy in addition to being male, younger and having lower education. Shame and perceived lack of knowledge about mental health could be barriers to service use and thus be useful targets for interventions meant to increase help-seeking rates. LPA is helpful for this purpose because it allows us to identify subgroups with homogeneous attitude patterns. Interventions are probably more efficient if they focus on members of a subgroup with consistently more sceptical views about professional sources of help who are more prone to underutilize available services. Initiatives that aim to increase service use by reducing (anticipated) shame about having a mental illness and by increasing perceived knowledge could consist of marketing campaigns addressing the general public (Jorm, 2012; Henderson et al. 2013), of more focused programs using education- and contactbased approaches with target groups (Corrigan et al. 2012), of selected or indicated prevention programmes for people at risk for mental illness (Compton, 2010; de Girolamo et al. 2012; Yap \& Jorm, 2012), or of more clinically oriented interventions among diagnosed individuals who have already entered the mental health service system (Yanos et al. 2011; Luoma et al. 2012; Corrigan et al. 2013).

\section{Acknowledgements}

We are grateful to all participants.

\section{Financial Support}

This study was supported by the Zürich Program for the Sustainable Development of Mental Health Services (www.zinep.ch).

\section{Ethical Standards}

The authors assert that all procedures contributing to this work comply with the ethical standards of the relevant national and institutional committees on human experimentation and with the Helsinki Declaration of 1975, as revised in 2008.

\section{References}

Angermeyer MC, Dietrich S (2006). Public beliefs about and attitudes towards people with mental illness: a review of population studies. Acta Psychiatrica Scandinavica 113, 163-179.

Angst J, Dobler-Mikola A, Binder J (1984). The Zurich study - a prospective epidemiological study of depressive, neurotic and psychosomatic syndromes. I. Problem, methodology. European Archives of Psychiatry and Neurological Sciences 234, 13-20.

Angst J, Gamma A, Rössler W, Ajdacic-Gross V, Klein DN (2009). Long-term depression versus episodic major depression: results from the prospective Zurich study of a community sample. Journal of Affective Disorders 115, 112-121.

Barney LJ, Griffiths KM, Jorm AF, Christensen H (2006). Stigma about depression and its impact on help-seeking intentions. Australian and New Zealand Journal of Psychiatry 40, 51-54.

Clement S, Brohan E, Jeffery D, Henderson C, Hatch SL, Thornicroft G (2012). Development and psychometric properties the barriers to access to care evaluation scale (BACE) related to people with mental ill health. BMC Psychiatry 12, 36.

Codony M, Alonso J, Almansa J, Bernert S, de Girolamo G, de Graaf R, Haro JM, Kovess V, Vilagut G, Kessler RC (2009). Perceived need for mental health care and service use among adults in Western Europe: results of the ESEMeD project. Psychiatric Services 60, 1051-1058.

Compton MT (2010). Clinical Manual of Prevention in Mental Health. American Psychiatric Publishing: Washington, DC.

Corrigan PW, Rüsch N (2002). Mental illness stereotypes and clinical care: do people avoid treatment because of stigma? Psychiatric Rehabilitation Skills 6, 312-334. 
Corrigan PW, Watson AC (2002). The paradox of self-stigma and mental illness. Clinical Psychology: Science and Practice 9, 35-53.

Corrigan PW, Morris SB, Michaels PJ, Rafacz JE, Rüsch N (2012). Challenging the public stigma of mental illness: a meta-analysis of outcome studies. Psychiatric Services 63, 963-973.

Corrigan PW, Kosyluk KA, Rüsch N (2013). Reducing self-stigma by coming out proud. American Journal of Public Health 103, 794-800.

de Girolamo G, Dagani J, Purcell R, Cocchi A, McGorry PD (2012). Age of onset of mental disorders and use of mental health services: needs, opportunities and obstacles. Epidemiology and Psychiatric Sciences 21, 47-57.

Derogatis LR (1977). SCL-90: Administration, Scoring, and Procedures Manual - I for the R(evised) Version and Other Instruments of the Psychopathology Rating Scale Series. Johns Hopkins University: Baltimore.

Edlund MJ, Wang PS, Berglund PA, Katz SJ, Lin E, Kessler RC (2002). Dropping out of mental health treatment: patterns and predictors among epidemiological survey respondents in the United States and Ontario. American Journal of Psychiatry 159, 845-851.

Evans-Lacko S, Little K, Meltzer H, Rose D, Rhydderch H, Henderson C, Thornicroft G (2010). Development and psychometric properties of the Mental Health Knowledge Schedule (MAKS). Canadian Journal of Psychiatry 55, 440-448.

Evans-Lacko S, Brohan E, Mojtabai R, Thornicroft G (2012). Association between public views of mental illness and self-stigma among individuals with mental illness in 14 European countries. Psychological Medicine 42, 1741-1752.

Griffiths KM, Christensen H, Jorm AF, Evans K, Groves C (2004). Effect of web-based depression literacy and cognitive-behavioural therapy interventions on stigmatising attitudes to depression: randomised controlled trial. British Journal of Psychiatry 185, 342-349.

Hardt J (2008). The Symptom Checklist-27-plus (SCL-27-plus): a modern conceptualization of a traditional screening instrument. Psychosocial Medicine 5, Doc08.

Henderson C, Evans-Lacko S, Thornicroft G (2013). Mental illness stigma, help seeking, and public health programs. American Journal of Public Health 103, 777-780.

Huxley P (1996). Mental illness in the community: the Goldberg-Huxley model of the pathway to psychiatric care. Nordic Journal of Psychiatry 50 (Suppl. 37), 47-53.

Jagdeo A, Cox BJ, Stein MB, Sareen J (2009). Negative attitudes toward help seeking for mental illness in 2 population-based surveys from the United States and Canada. Canadian Journal of Psychiatry 54, 757-766.

Jorm AF (2012). Mental health literacy: empowering the community to take action for better mental health. American Psychologist 67, 231-243.

Jorm AF, Wright A (2007a). Beliefs of young people and their parents about the effectiveness of interventions for mental disorders. Australian and New Zealand Journal of Psychiatry 41, 656-666.

Jorm AF, Medway J, Christensen H, Korten AE, Jacomb PA, Rodgers B (2000). Public beliefs about the helpfulness of interventions for depression: effects on actions taken when experiencing anxiety and depression symptoms. Australian and New Zealand Journal of Psychiatry 34, 619-626.

Jorm AF, Griffiths KM, Christensen H, Parslow RA, Rogers B (2004). Actions taken to cope with depression at different levels of severity: a community survey. Psychological Medicine 34, 293-299.

Jorm AF, Wright A, Morgan AJ (2007b). Where to seek help for a mental disorder? National survey of the beliefs of Australian youth and their parents. Medical Journal of Australia 187, 556-560.

King D, Knapp M, Patel A, Amaddeo F, Tansella M, Schene A, Koeter M, Angermeyer M, Becker T (2013). The impact of non-adherence to medication in patients with schizophrenia on health, social care and societal costs: analysis of the QUATRO study. Epidemiology and Psychiatric Sciences, 1-10. doi:10.1017/S2045796013000097.

Lanfredi M, Rossi G, Rossi R, van Bortel T, Thornicroft G, Quinn N, Zoppei S, Lasalvia A (2013). Depression prevention and mental health promotion interventions: is stigma taken into account? An overview of the Italian initiatives. Epidemiology and Psychiatric Sciences, 1-12. doi:10.1017/S2045796013000085.

Lasalvia A, Zoppei S, van Bortel T, Bonetto C, Cristofalo D, Wahlbeck K, Bacle SV, van Audenhove C, van Weeghel J, Reneses B, Germanavicius A, Economou M, Lanfredi M, Ando S, Sartorius N, Lopez-Ibor JJ, Thornicroft G (2013). Global pattern of experienced and anticipated discrimination reported by people with major depressive disorder: a cross-sectional survey. Lancet 381, 55-62.

Lauber C, Nordt C, Falcato L, Rössler W (2001). Lay recommendations on how to treat mental disorders. Social Psychiatry and Psychiatric Epidemiology 36, 553-556.

Link BG (1987). Understanding labeling effects in the area of mental disorders: an assessment of the effects of expectations of rejection. American Sociological Review 52, 96-112.

Lo Y, Mendell NR, Rubin DB (2001). Testing the number of components in a normal mixture. Biometrika 88, 767-778.

Luoma JB, Kohlenberg BS, Hayes SC, Fletcher L (2012). Slow and steady wins the race: a randomized clinical trial of acceptance and commitment therapy targeting shame in substance use disorders. Journal of Consulting and Clinical Psychology 80, 43-53.

MacKinnon DP, Fairchild AJ, Fritz MS (2007). Mediation analysis. Annual Review of Psychology 58, 593-614.

McLachlan G, Peel D (2000). Finite Mixture Models. Wiley: New York.

Müller M, Vetter S, Buchli-Kammermann J, Stieglitz RD, Stettbacher A, Riecher-Rössler A (2010). The Self-screen-Prodrome as a short screening tool for pre-psychotic states. Schizophrenia Research 123, 217-224.

Muthén LK, Muthén BO (2002). How to use a Monte Carlo study to decide on sample size and determine power. Structural Equation Modeling 4, 599-620.

Muthén LK, Muthén BO (2011). Mplus User's Guide. Muthén \& Muthén: Los Angeles.

Nylund KL, Asparouhov T, Muthén B (2007). Deciding on the number of classes in latent class analysis and growth mixture modeling: a Monte Carlo simulation study. Structural Equation Modeling 14, 535-569. 
Phelan JC, Yang LH, Cruz-Rojas R (2006). Effects of attributing serious mental illnesses to genetic causes on orientations to treatment. Psychiatric Services 57, 382-387.

Riedel-Heller SG, Matschinger H, Angermeyer MC (2005). Mental disorders - who and what might help? Help-seeking and treatment preferences of the lay public. Social Psychiatry and Psychiatric Epidemiology 40, 167-174.

Rose D, Willis R, Brohan E, Sartorius N, Villares C, Wahlbeck K, Thornicroft G (2011). Reported stigma and discrimination by people with a diagnosis of schizophrenia. Epidemiology and Psychiatric Sciences 20, 193-204.

Rüsch N, Hölzer A, Hermann C, Schramm E, Jacob GA, Bohus M, Lieb K, Corrigan PW (2006). Self-stigma in women with borderline personality disorder and women with social phobia. Journal of Nervous and Mental Disease 194, 766-773.

Rüsch N, Corrigan PW, Bohus M, Jacob GA, Brueck R, Lieb K (2007a). Measuring shame and guilt by self-report questionnaires: a validation study. Psychiatry Research 150, 313-325.

Rüsch N, Lieb K, Göttler I, Hermann C, Schramm E, Richter H, Jacob GA, Corrigan PW, Bohus M (2007b). Shame and implicit self-concept in women with borderline personality disorder. American Journal of Psychiatry 164, 500-508.

Rüsch N, Corrigan PW, Wassel A, Michaels P, Larson JE, Olschewski M, Wilkniss S, Batia K (2009a). Self-stigma, group identification, perceived legitimacy of discrimination and mental health service use. British Journal of Psychiatry 195, 551-552.

Rüsch N, Corrigan PW, Wassel A, Michaels P, Olschewski M, Wilkniss S, Batia K (2009b). Ingroup perception and responses to stigma among persons with mental illness. Acta Psychiatrica Scandinavica 120, 320-328.

Rüsch N, Todd AR, Bodenhausen GV, Weiden PJ, Corrigan PW (2009c). Implicit versus explicit attitudes toward psychiatric medication: implications for insight and treatment adherence. Schizophrenia Research 112, 119-122.

Rüsch N, Corrigan PW, Todd AR, Bodenhausen GV (2010). Implicit self-stigma in people with mental illness. Journal of Nervous and Mental Disease 198, 150-153.

Rüsch N, Evans-Lacko S, Henderson C, Flach C, Thornicroft G (2011). Knowledge and attitudes as predictors of intentions to seek help and disclose a mental illness. Psychiatric Services 62, 675-678.

Schomerus G, Angermeyer MC (2008). Stigma and its impact on help-seeking for mental disorders: what do we know? Epidemiologia e Psichiatria Sociale 17, 31-37.
Schomerus G, Matschinger H, Angermeyer MC (2009). The stigma of psychiatric treatment and help-seeking intentions for depression. European Archives of Psychiatry and Clinical Neuroscience 259, 298-306.

Schomerus G, Auer C, Rhode D, Luppa M, Freyberger HJ, Schmidt S (2012a). Personal stigma, problem appraisal and perceived need for professional help in currently untreated depressed persons. Journal of Affective Disorders 139, 94-97.

Schomerus G, Schwahn C, Holzinger A, Corrigan PW, Grabe HJ, Carta MG, Angermeyer MC (2012b). Evolution of public attitudes about mental illness: a systematic review and meta-analysis. Acta Psychiatrica Scandinavica 125, 440-452.

Thornicroft G (2007). Most people with mental illness are not treated. Lancet 370, 807-808.

Thornicroft G (2012). No time to lose: onset and treatment delay for mental disorders. Epidemiology and Psychiatric Sciences 21, 59-61.

Vogel DL, Wade NG, Haake S (2006). Measuring the self-stigma associated with seeking psychological help. Journal of Counseling Psychology 53, 325-337.

von Eye A, Bergman LR (2003). Research strategies in developmental psychopathology: dimensional identity and the person-oriented approach. Development and Psychopathology 15, 553-580.

Wang PS, Aguilar-Gaxiola S, Alonso J, Angermeyer MC, Borges G, Bromet EJ, Bruffaerts R, de Girolamo G, de Graaf R, Gureje O, Haro JM, Karam EG, Kessler RC, Kovess V, Lane MC, Lee S, Levinson D, Ono Y, Petukhova M, Posada-Villa J, Seedat S, Wells JE (2007). Use of mental health services for anxiety, mood, and substance disorders in 17 countries in the WHO world mental health surveys. Lancet 370, 841-850.

Yanos PT, Roe D, Lysaker PH (2011). Narrative Enhancement and Cognitive Therapy: a new group-based treatment for internalized stigma among persons with severe mental illness. International Journal of Group Psychotherapy 61, 576-595.

Yap MB, Jorm AF (2012). Parents' beliefs about actions they can take to prevent depressive disorders in young people: results from an Australian national survey. Epidemiology and Psychiatric Sciences 21, 117-123.

Yap MB, Reavley NJ, Jorm AF (2013). The associations between psychiatric label use and young people's help-seeking preferences: results from an Australian national survey. Epidemiology and Psychiatric Sciences, 1-9. doi:10.1017/S2045796013000073. 